\title{
Genki: A Case Study of Benefits for Foreigners Producing Theatre in a Japanese Regional Dialect
}

\author{
Philip Head \\ Osaka Jogakuin University
}

\begin{abstract}
This paper describes the Genki Tosaben Musical (Genki), a unique community theatre project in Kochi prefecture in Japan. Since 1996, foreigners living in Kochi have been creating original musical theatre productions in Tosaben, the local Japanese dialect, and touring the prefecture to raise money for charity and promote cross-cultural exchange. In this study, qualitative survey responses from 35 former participants in Genki were analyzed. Based on these survey responses, this paper explores the motivations of the participants in this production, how the experience impacted language learning and community integration, as well as the positive and negative aspects of partaking in this event.
\end{abstract}

\section{Introduction}

When people imagine theatre in Japan they may picture the traditional arts such as Kabuki, Noh, or even Takarazuka. However, in Kochi prefecture there is a truly distinctive theatre experience, the Genki Tosaben Musical (Genki). An equivalent to this theatre event for English speakers would be if a group of non-native English-speaking international students in the Scottish Highlands, Newfoundland in Canada, or the Appalachians in the US decided to perform for the locals in their own dialects, which even compatriots may have difficulty in understanding or even disparage. To better understand placement of this unique Japanese-speaking theatre event within the context of place, this paper first describes the Tosaben dialect and the history and operation of Genki. This is followed by a brief overview of the benefits of theatre in terms of language learning and motivation. Finally, there is a discussion of the research results. 


\section{Tosaben Dialect}

While standard Japanese (hyojungo), based on the Tokyo area dialect, is taught in schools nationally, Japan has many dialects (see Hattori, 2019 for an overview). These dialects formed in large part based on movement restrictions due to geographical factors such as mountains or seas separating areas, with some dialects being almost mutually incomprehensible (Lorant, 2014). Kochi Prefecture is home to two dialects, Tosaben and Hataben, with Tosaben being spoken in the provincial capital of Kochi City and the eastern regions of the prefecture, and Hataben in the western areas (Takahashi, 2010). Tosaben is related to Kansaiben, the regional dialect of Osaka and Kyoto; however, it differs due to the geographical isolation of Kochi, with the mountains on one side and the Pacific Ocean on the other (Yoshida, 2010). Tosaben features distinct grammar (Sato, 2010) and expressions (Yasutake \& Yuen, 2010) which can deviate from both Kansaiben and standard Japanese, hyojungo. For example, saying "to know" and "do not know" in hyojungo is shiteru and shiranai respectively, whereas they are shichu and shiran in Tosaben. Tosaben is also one of the dialects that contains many archaic phonological and grammatical features that have not been used in standard Japanese following the Meiji Restoration in the 1800s (Lorant, 2014). This can make Tosaben challenging even for advanced speakers of Japanese to understand casual conversation among locals, especially older residents, as well as children who have yet to be taught hyojungo in school. There is also a great deal of pride in the local dialect which is often featured in tourism campaigns as well as local business names and products. This is reflective of the changing attitudes towards dialects following the end of the second world war, when hyojungo was less strictly forced on school children, leading to a greater interest in dialects after the 1970s (Okumura, 2016). With this in mind, understanding a local dialect can be a source of linguistic capital for Japanese L2 speakers as they interact with members of their local communities (Takeuchi, 2015). In addition, willingness to communicate (WTC) (Yashima, Zenuk-Nishide, \& Shimizu, 2004) in Tosaben can be an effective way to connect with the local community. This is particularly relevant for foreigners in a largely rural prefecture such as Kochi, as we will see in the next section.

\section{The Genki Tosaben Musical}

To understand the creation and success of Genki, it is useful to look at some of the particular features of Kochi. Within the 47 prefectures of Japan, Kochi is one of the more rural, isolated, and monocultural. According to Statistics Japan, Kochi prefecture has the $4^{\text {th }}$ lowest population density of the 47 prefectures, and has the $5^{\text {th }}$ lowest ratio of foreigners to 
Japanese residents at $0.65 / 100$ residents compared to 2.16/100 nationally and 4.11/100 in Tokyo (2021b). Of the 4580 foreign residents registered in Kochi in 2018, people from English speaking countries are few, with 185 Americans and 51 British citizens registered (Statistics Japan, 2021a). This often results in Japan Exchange Teaching (JET) Programme participants, either as Assistant Language Teachers (ALTs) and Coordinators of International Relations (CIRs), being the only visibly non-Japanese, English-speaking residents of various small towns. This has the potential to lead to feelings of isolation and stress for the JET participants and provides an impetus towards integration into both the local Japanese community as well as the community of foreigners as it is important for social well-being. This may be especially true for JETs who are living alone in a foreign country for the first time in their lives.

In part to help promote connections and cross-cultural understanding between JETs and the local community, the GENKI Youth Association (GENKI Seinen-kai) has been creating original musical theatre performances (the Genki Tosaben Musical, aka Genki) in Tosaben every year since 1996 until 2020, the first time that the performance was cancelled, which was due to COVID-19. The subsequent 2021 performance was moved online (GENKI Youth Association, 2021a; 2021b). Each play is written from zero each year and typically combines western plots with historical Kochi figures and local legends (see GENKI Youth Association, 2021b for past performance titles).

A typical timeline of the production involves a team of writers meeting in the fall to develop an overall theme, with each act of the play assigned to a different writer (in English or Japanese) which is then translated into Tosaben by local Japanese volunteers. In January/ February, volunteer audition for roles. During the audition, actors are initially asked for their commitment limitations in order to decide the size of role, before performing a song of their choice, and a short reading. Actors may have multiple roles depending on the number of volunteers each year, and may also assist with prop design, choreography, or directing. Rehearsals take place in Kochi City on weekends throughout February and March, with performances taking place across the prefecture during the first two weekends in April. While on tour, traveling by bus or other forms of privately shared transportation, there are two to three performances per day, with the final and largest performance taking place in Kochi City. There is no admission charge for the performances, although afterwards the audience is asked to donate money towards scholarships for local students to study abroad.

The costs of the production (venue rental, costumes, and transportation) are predominantly bourn by the volunteers (often contributing over 10,000 yen per person), 
although there is some outside support, such as storage space provided by the local government and free venue rental at some performance locations. The participants are usually JET Programme participants, however in the past international students and private dispatch company ALTs have also participated. In addition, there are usually some local Japanese volunteers ("Tosaben Masters") who help with script checks, line coaching, and lighting or other activities while on tour.

\section{Literature Review}

Numerous studies have shown that theatre and drama can have beneficial foreign language learning effects (Carson, 2012; Dodson, 2002; Horghagen \& Josephsson, 2010; Ryan-Scheutz \& Colangelo, 2004). These benefits can be seen in terms of the improvement of specific language skills as well as motivation (Barbee, 2016).

Theatre lends itself to Task-Based Learning as it engages learners' interest, has a focus on meaning, is assessed on the outcome, requires completion, and is a 'real-life' activity (Carson, 2012). According to Raquel (2015), the nature of theatre immerses learners in a language with scripts using spoken grammar and involves an emphasis on speaking, requiring pronunciation, intonation, and expression practice. In addition, there is reading practice and vocabulary acquisition through line memorization. Finally, performing in a foreign language on a public stage may help to increase confidence in speaking off-stage (Dodson, 2002). There can also be an increase in knowledge of the target culture through idioms and immersion in authentic texts (RyanScheutz \& Colangelo, 2004).

Theatre also involves multiple types of motivation for language learning. One common way of looking at motivation is the intrinsic (internal rewards such as the joy of doing an activity) and extrinsic (getting rewards such as grades or praise or avoiding punishments from outside sources) motivational dichotomy, with intrinsic motivation considered most powerful (Dornyei, 1994). In theatre there are many sources of extrinsic motivation such as having to meet a performance deadline and the expectations of the audience and fellow actors. However, there is clearly intrinsic motivation as well, with actors challenging themselves to take on new and bigger roles.

Although motivation for language learning is complex, one of the most important contexts is when learners live in the target language community, which can be defined as integrative motivation. This can be broadly defined as "a positive disposition toward the L2 group and the desire to interact with and even become similar to valued members of that community" (Dornyei, 1994, p.274). Although most studies on the benefits of theatre have 
dealt with students rather than adults in society, previous research with refugees in Norway found that theatre participation helped with both social connections among participants, as well as increased engagement with the local Norwegian community and motivation to learn Norwegian (Horghagen \& Josephsson, 2010). While such studies show the benefits of theatre for marginalized groups such as refugees, the benefits for a minority (but relatively privileged) group such as ALTs living in Japan have not been extensively researched thus far. The research questions in this study aim to fill this gap in the literature.

\section{Research Questions}

This paper describes how participation in a musical using Tosaben can influence language learning and community integration in general. This differs from many other studies which have typically researched students studying a foreign language in classroom-based situations with various degrees of autonomy but ultimately under the supervision and/or control of a teacher. In contrast, Genki is entirely volunteer-driven and community-led, with no official authority figure, classroom accountability or final grade. In this way, Genki can be seen as a successful long-term, community building project. Through the experiences of past participants, this paper examines the following questions (see Appendix A for responses to other questions):

1. Why do people decide to join Genki?

2. What effect did participating in Genki have on peoples' Japanese language learning?

3. How did joining Genki affect community integration?

4. What are the positive and negative aspects of participation in Genki?

\section{Methodology}

This project involved describing and reporting on four of nine qualitative responses to a survey (see Appendix A) submitted by 35 former Genki participants. The survey featured open-ended questions and was anonymous. A link to the survey was posted on the Kochi AJET Facebook page on August 8, 2021 (Kochi_AJET, n.d.), a place where current and former Kochi JETs interact online. In addition, direct requests were sent to former participants. Although respondents could have participated at any time since the inception of Genki, it is likely that most respondents would have partaken between 2009 and 2015 as these were the participants who were directly contacted with requests. The responses were coded and grouped into different categories to ascertain emergent trends. 


\section{Results}

This section examines the responses to the survey questions, with answers grouped into themes, the total number of responses in each group reported, and representative quotations included for each group. This is followed by a summary of the overall trends in the data for each question. Responses to the survey were free form; therefore some responses submitted may be complex and touch on, and be grouped into, more than one theme.

\section{Participant Profiles}

In order to ascertain basic information, participants were asked a number of questions pertaining to active participant years (Table 1), their roles (Table 2), and approximate Japanese language ability on joining (Table 3).

\section{Table 1}

Total number of years participants were involved with Genki

\begin{tabular}{cc}
\hline Total number of years & Number of responses $(n=35)$ \\
\hline 1 & 9 \\
2 & 10 \\
3 & 12 \\
4 & 2 \\
5 & 2 \\
\hline
\end{tabular}

As can be seen in Table 1, most participants were involved in Genki for more than one year, indicating that many found the experience worth repeating. It should also be noted that JETs are limited to working for a maximum of five years (maximum three years prior to 2007) (CLAIR, n.d.), so some respondents may have participated every year that they resided in Kochi. 


\section{Table 2}

Types of participant roles in Genki

\begin{tabular}{lc}
\hline Types of roles & Number of responses \\
\hline Actor (minor role) & 11 \\
Actor (major role) & 22 \\
Director & 8 \\
Writer & 5 \\
Choreographer & 3 \\
Props and lighting & 6 \\
\hline
\end{tabular}

Table 2 indicates that the participant responses to the survey represent a wide variety of roles and experiences within this production. It should be noted that people may have had more than one role during a given production and may also have tried different roles in different years, resulting in a total number of roles greater than the number of participants.

\section{Table 3}

Participants' approximate Japanese ability on joining Genki

\begin{tabular}{lc}
\hline Japanese level & Number of respondents $(\mathrm{n}=35)$ \\
\hline Basic/survival & 12 \\
Intermediate/conversational & 14 \\
Advanced/fluent & 9 \\
\hline
\end{tabular}

As shown in Table 3, there was a wide range of self-reported Japanese abilities among the participants. Some had not taken the Japanese Language Proficiency Test (JLPT), but for those who had, the self-described ranges corresponded as follows:

- Basic/survival: N5-4

- Intermediate/conversational: N4-2

- Advanced/fluent N2-1. 


\section{Reasons for participation}

\section{Table 4}

Participant responses to the question "What were your reasons for participating in Genki?"

Type of Response (number) Sample Quotation (participant code)

To make friends and become “Other JETs in my area were participating and I didn't

part of the foreigner

want to be left out" (P4)

community (18)

Having a love of theatre and

"I love musicals in general, and I love to sing and

performing (17) dance" (P5)

Wanting to improve Japanese

"I love theatre, improving my language acquisition and and Tosaben ability (13) challenging myself." (P18)

Wanting to reach out to the local community (8)

A desire to volunteer and work for charity (6)

It looked like a fun activity (5)

It was something to do during the winter months (4)

It was recommended (4)

It was easy to join (2)

Wishing to travel around the prefecture (2)
"I was drawn to the positive influence that Genki could have on the local community." (P35)

“...I was interested in community outreach/charity..." (P1)

“It looked like a fun and unique experience." (P10)

“... I needed something to do during the winter. It was getting cold and I was starting to get a little bit depressed.” (P29)

"One of the first things that veteran JETs had told me when I arrived in Kochi was how much fun Genki was. (They were right.)" (P8)

"I never thought of myself as much of an actor, but the organizers made it very clear that everyone was welcome and there were no prerequisites." (P5) "...a good opportunity to visit other parts of the prefecture.” (P13) 
As the above responses show, the ability to form social connections with both other foreigners and the local community makes up a large part of the motivation for joining Genki. In addition, many people joined because of a pre-existing love of theatre and performance, while others see the experience as a way to challenge themselves and learn new skills (both in terms of language learning and performance).

\section{Participation Japanese language motivation}

\section{Table 5}

Participant responses to the question "Did participating in Genki affect your motivation/ability to speak Japanese? If yes, how? If not, why not?"

Reason for Response (number) Sample Quotation (participant code)

\section{Positive}

Increased interest in learning

Tosaben specifically (14)

Improvements in pronunciation and intonation (10)

Increased motivation to study Japanese (7)

Improvement in vocabulary and/or grammar (6) Increased confidence to speak Japanese (5)
"As a result of being exposed to Tosaben I slowly learned words, grammar and the specifics of Tosaben pronunciation and it made me want to learn more" (P29)

"...the rehearsals and emphasis on intonation and accent helped reinforce natural speech patterns" (P15)

"Participating in Genki Musical did motivate me to learn more Japanese and appreciate collaboration between foreigners and Japanese people.” (P10) "I learned a good deal of vocabulary from memorizing lines" (P5) "It definitely helped bolster my confidence in learning Japanese, after the first year as a cast member I walked away with feeling that if I could manage Tosaben I can manage regular Japanese just fine." (P9) 
Inspired to study by watching

other participants (4)

Being better able to talk with the local community (4)

Appreciated direct feedback from Tosaben native speakers on speaking (3)

Improving kanji reading (1)

Neutral or Mixed

Already proficient in Japanese and so saw no improvements

Had few or no lines to speak and so didn't need to practice Japanese (2)

Felt non-standard Japanese wasn't useful outside of Kochi

Too busy rehearsing GENKI to study Japanese (1)

Negative

Difficulty using Tosaben decreased confidence in standard Japanese ability (1)
"I wanted a bigger role in order to improve my Japanese but my role had one speaking line over and over, so I was a little disappointed, but I learned from watching other people rehearse." (P1) “...it actually helped when conversing particularly with older people in my town, especially using the different verb conjugations, because of how strong their Tosaben could be" (P24)

"Yes, it was motivating to have small group tuitions with a native speaker." (P25)

"...by translating the script I was able to increase the amount of kanji I knew.” (P30)

"I was already in a town where I had to speak [Japanese] all day, so I actually spoke more English in GENKI than in my workdays" (P11) “Honestly, probably not. It just wasn't really needed behind the curtain" (P13)

"Although it was fun at the time whilst in Kochi, I was conscious of sounding like a 'country men' everywhere else in Japan i.e. Tokyo" (P34)

"I was so busy most of the time that I didn't have a chance to focus on learning Japanese beyond what was required for my role.” (P35)

"It kind of negatively affected my motivation in that the Tosaben dialect and accent was hard to mimic, and it made me wonder if my standard Japanese was up to par. I knew then as I know now that it was irrational thinking but it did make me feel a bit insecure.” (P3) 
As can be seen from Table 5 above, for the majority of participants, participating in Genki had a positive effect on motivation and various aspects of learning Japanese, such as speaking, confidence, and vocabulary, although there was no one specific aspect of language learning that improved, according to the respondents' information.

\section{Community relationships}

\section{Table 6}

Participant responses to the question "Did participating in Genki affect your relationship with the community (co-workers, students, other foreign residents)? If yes, how? If not, why not?"

\begin{tabular}{l}
\hline $\begin{array}{l}\text { Reason for Response } \\
\text { (number) }\end{array}$ \\
\hline
\end{tabular}

Positive effect

Strengthened relationships "Definitely helped me get to know other JETs" (P13)

with the other foreign

residents participating (26)

Improved co-worker relations "I found my coworkers appreciated my effort as I believed it showed my investment in the community." (P18)

Bonding with the local "With the local Japanese community, I made friends with community (9) people who I would not have otherwise met, such as local translators, event space organizers, media personnel, etc." (P30)

Making friends with the Japanese volunteers (8) "My coworkers and students were not involved but I did make friends with Japanese native volunteers too.” (P19) Improved relations with "Some of my students and teachers from the school were students (5) there. I became a sort of 'mini celeb' when went back to school." (P34)

Mixed effect

Personality conflicts with "It strengthened some relationships while at the same time some production members (2) souring others, especially the bossy, easily-irritable members." (P3) 
No effect

Lack of interest from their

"my office didn't really care about the musical,

office colleagues (1) unfortunately, as they had different priorities at the time." (P6)

\section{Table 7}

Reasons for positive responses to the question "Did participating in Genki affect your relationship with the community (co-workers, students, other foreign residents)?

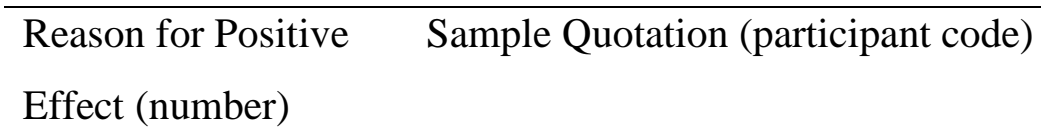

Bonding with others "my co-workers and students were highly supportive of me over learning participating in Genki and would actually help me with my lines Tosaben (6) during down-time at school." (P30)

Having a reason to "I'm fairly shy and having a shared project over a period of time interact with others allowed me to get to know people, and gave me the time to come out of my shell." (P5)

Enjoyed travelling to "touring Kochi with our production and seeing the reaction of other places in the Japanese people to the performance did make me feel closer to the prefecture and Japanese community" (P10)

leaving their small towns (5)

This project brings "I think the play attracted people with similar interests (such as people with similar community involvement and artistic performance), which helped interests together (2) me to be comfortable and become friends with them" (P21) 
Participating in Genki was overwhelmingly positive in terms of social connections, both within the foreigner community and with the local Japanese community (Table 6). This was due both to having increased reasons and opportunities to interact with others, as well as mutual respect for the local culture which was a factor in developing meaningful relationships with the local community (Table 7).

\section{Positive participation results}

\section{Table 8}

Responses to the question "What was the best thing about participating in Genki? Why?"

Type of Response Sample Quotation (participant code)
(number)

Spending time with cast

"Making friends with other JETs and hanging out. I really members (24) struggled getting out and socializing, especially from being out in the countryside, so being part of Genki got me in contact with amazing and fun people and I'm super grateful for that." (P24)

The experience of "Working with other cast members, particularly when it came to making the show and the songs and dancing, was a lot of fun." (P1)

performing (16)

Making connections "Working together to create something and building a with the local connection between JETs and the people of Kochi.” (P18)

community (9)

Improvements in Japanese language ability and confidence "I'm really proud of the way I went from being unable to read a (6) complete line of Japanese/Tosaben to being able to read my lines (with Kanji) perfectly and recite my lines almost perfectly..." (P7)

The touring experience "Touring the prefecture was such a blast, I looked forward to it every year." (P5)

The freedom to choose roles (2)

"I loved how free we were to define our own roles (e.g. Composing songs, directing, producing set/props)" (P6) 
The above responses closely correspond with the reasons for participating in Genki (Table 4), indicating that many participants received their desired outcome. In particular, Genki allowed closer relationships within the Genki community (both foreign cast members and local Japanese volunteers), as well as with the local Japanese community. However, the process of creating and touring the theatre production itself was a highlight for many people. In addition, many people felt that their Japanese knowledge and confidence improvements were a major positive.

\section{Negative participation results}

\section{Table 9}

Responses to the question "What were some problems with participating in Genki? Why?"

\begin{tabular}{|c|c|}
\hline $\begin{array}{l}\text { Type of Response } \\
\text { (number) }\end{array}$ & Sample Quotation (participant code) \\
\hline $\begin{array}{l}\text { Long rehearsals and } \\
\text { scheduling } \\
\text { problems (14) }\end{array}$ & $\begin{array}{l}\text { "I had to sit around long hours during rehearsal a lot [because] I had } \\
\text { a small role." (P1) }\end{array}$ \\
\hline $\begin{array}{l}\text { Issues with other } \\
\text { cast members' } \\
\text { commitment and } \\
\text { ability (9) }\end{array}$ & $\begin{array}{l}\text { "Inevitably there is drama. It's an intense four months, and it is hard } \\
\text { for people to commit to the entire time, skills aren't always a match, } \\
\text { interpersonal conflicts happen. Depending the level of commitment, } \\
\text { you can get some people pulling some hellish sabotage on the } \\
\text { others." (P2) }\end{array}$ \\
\hline $\begin{array}{l}\text { Interpersonal } \\
\text { conflicts (8) }\end{array}$ & $\begin{array}{l}\text { “...the leadership was a bit impatient at times and didn't really treat } \\
\text { us with respect during the tour" (P1) }\end{array}$ \\
\hline $\begin{array}{l}\text { Lack of community } \\
\text { support and } \\
\text { knowledge (7) }\end{array}$ & $\begin{array}{l}\text { "... outside of the flyer and a radio appearance, there was little } \\
\text { effort put into promotion therefore we didn't get the exposure } \\
\text { necessary to raise awareness or receive additional donations." (P1) }\end{array}$ \\
\hline $\begin{array}{l}\text { Problems with } \\
\text { having too many } \\
\text { creators (4) }\end{array}$ & $\begin{array}{l}\text { "... since each act is traditionally written by a different person, the } \\
\text { play can seem very disjointed and completely nonsensical with no } \\
\text { running plot. ... I don't think crating a play works as a coop, I think } \\
\text { you need a dedicated writer or director creating a plot and story that } \\
\text { makes sense." (P16) }\end{array}$ \\
\hline
\end{tabular}




\begin{tabular}{ll}
\hline $\begin{array}{l}\text { Long travel times } \\
\text { from remote areas }\end{array}$ & "Kochi is quite a big prefecture and the fact that everything was run \\
to the rehearsal & was inevitably a lot bigger in order to account for hours of travel \\
venue (4) & every weekend." (P6) \\
Having to & "Cast and crew had to contribute a lot of money in order for the \\
contribute money & show to even [happen] and in the end, we could've just pooled that \\
(2) & money into the donation pot and ended up with more money than we \\
& actually raised from performances." (P1)
\end{tabular}

Problems with equipment and facilities (2) "There was no technical training for equipment we would borrow at venues, and some equipment was old and not safe to use (for example, some of the lighting switches would be sparking) which greatened the risk to some people's safety." (P19)

Memorizing (1) "My Japanese wasn't strong at the time and it was in a new dialect not taught in books. Only way was just to 'memorize"' (P34)

Nothing (3) "No problems.” (P33)

As the above comments illustrate, when a large, volunteer-driven community theatre project is created, fostering positive interpersonal relationships and proper organization are essential to the proper functioning of the endeavor. Problems occur when there is a lack of clear authority for creative decisions and a lack of consequences for non-fulfillment of duties. In addition, proper organization in terms of scheduling and promotion is essential for lessening the burden on individual cast members as well as making the production successful in terms of community engagement (the ultimate goal of a performance).

\section{Discussion}

The Genki Tosaben Musical is a unique event combining intercultural communication, community integration, charity, and language learning through theatre. In order to better understand this production, we used the results of a survey that included responses from a wide variety of participants in terms or their roles, Japanese language ability, and number of times that they participated. This paper focused on four main areas; 
motivation to join Genki, how participation affects language learning, the effect on community integration, and the experience of participation itself (both positive and negative).

By describing the experiences of past participants in this production, future participants in Genki, or other productions that wish to emulate it, can see what has been successful thus far, while also learning about potential problems and how to avoid them.

\section{Participation motivation}

There were many factors for participant motivation and respondents often reported more than one reason for participation. However, it seemed that social connections, within both the foreigner community and the local Japanese community, was the main factor. It is important to remember that, as many JETs were placed in small rural towns, there were few opportunities for interaction with other English-speaking people of the same age. In addition, the strong Tosaben dialect of the locals can create an additional barrier to communication, even among those JETs already proficient in Japanese. Thus, a project like Genki that could bring people together helped give participants reason and opportunity to interact with others, potentially helping their integration into the community and aiding mental health. In addition, many people had a pre-existing love of performance and so were motivated to participate irrespective of circumstances, while others hoped to gain increased knowledge of Japanese and Tosaben. These aspects were all interconnected: the shared love of performance helped in forming social connections with other Genki members and the increased ability to communicate in Tosaben with the local community resulted in increased interactions with all members of the Kochi community.

\section{Language learning}

It should be noted that the explicit goal of Genki is not language learning, but rather community outreach and cross-cultural understanding (GENKI Youth Association, 2021a). Furthermore, the participants in Genki were almost in all full-time workers, rather than students of Japanese, though many had studied Japanese previously or were in the process of studying, and had a wide range of prior Japanese knowledge and abilities. However, most interactions off-stage were in English.

Although language learning was not the most common or primary motivation for initial signup to Genki, nonetheless many participants reported improvements in Japanese language learning in terms of motivation and ability. Other improvement can be expected in the context of theatre in terms of line memorization and extensive speaking practice. In the 
case of Genki, actors had opportunities to get personalized help with speaking nuance from local volunteers, and even actors already proficient in standard Japanese could challenge themselves to learn an additional dialect.

Since Tosaben is such a key feature of the local community identity, by learning this dialect actors indicated that they were able to integrate into the community easier than if they only spoke standard Japanese. This ability to connect with local residents in the workplace and within the larger community proved to be a powerful motivator in Japanese language acquisition and lead to more opportunities to practice daily outside the theatre rehearsals and production.

\section{Community integration}

In terms of community integration, through Genki there were two communities involved: the multinational English-speaking (mostly JET) foreigner community and the local Japanese community. Respondents indicated that participating in Genki was generally helpful in becoming part of both of these communities. In terms of the foreign community, it gave a people reason to gather together and a shared project to bond over. For the local community, participation served as an icebreaker and an indication of respect for local culture, helping to break down barriers at work and within the community. The only caveat to these positive experiences was that interpersonal relationships could sour due to personality clashes rather than issues of cross-cultural discord.

\section{Lessons from both positive and negative experiences}

In terms of the positive and negative aspects of Genki itself, most respondents were positive about the experience. The majority of the positive aspects mirrored the reasons that respondents gave for originally signing up: increased social contacts with other cast members, the performance experience, learning Japanese, and making connections with the local community, and Genki delivered. In addition, the sense of purpose for each production had many benefits. Since Genki was a fundraiser for local student study abroad scholarships, there was a sense of doing good within the local community for the participants. This fundraising aspect also helped to build the local community investment in the production as it gave a concrete reason to support and attend the endeavor beyond the simple novelty of seeing foreigners speaking in the local dialect. However, there were also frustrations with regards to efficiency in terms of the money raised juxtaposed with the effort invested in the production. 
Although interpersonal relationships often improved as a result of participating in Genki, they were also the source for negative experiences. In particular, in a group effort such as theatre production, if certain cast members do not fulfill the demands required of their role, this can result in additional stress for everyone else. Another issue was that, for members living outside of Kochi City, there were many additional demands in terms of longer commute times, therefore efficient scheduling was important to minimize this burden. Finally, despite the ability to perform multiple types of roles being considered positive, having a large number of people in creative roles sometimes lead to problems with story coherence. As there was no overall authority figure responsible for the production, it became difficult to accommodate interpersonal conflicts and other issues. Notwithstanding, by offering a wide variety of acting roles both main cast and minor parts, as well as a variety of participation methods (writing, directing, choreography, prop/costume construction, and technical support), many participants appreciated being able to find suitable roles for their talent and commitment.

\section{Study limitations}

Genki is an entirely volunteer driven enterprise and, as a result, the conclusions reached in this paper may not directly apply to other situations, such as when participation is required for course credit. In addition, the participants surveyed were recalling events that took place several years prior, and so some of the more detailed memories may have faded. Finally, all language learning benefits were based on subjective recollection as opposed to concrete pre- and post-test results. Therefore, future researchers may wish to examine these perceived increases in skills quantitatively or compare them to results of a control group of JETs who did not participate in order to more objectively measure the effects.

\section{Conclusion}

In summary, regardless of the role, participants in Genki generally had a positive experience, particularly in terms of community integration and social connection. There were also many benefits in terms of language learning (both standard Japanese and Tosaben), although this was not the primary motivation for most participants to join Genki.

However, based on the results of this study, some general recommendations can be given for future Genki productions or for others who may wish to recreate this experience elsewhere. First, it should be noted that in a group effort like theatre production, the commitment of individuals is important for the successful functioning of the group. If one 
individual does not fulfill their role, this can create a burden on all the other members of the group and has the potential to sabotage the entire production. While members of the group can grow closer through their shared experiences, personality conflicts can also be exacerbated, ultimately leading to a breakdown in relationships. With this in mind, clear communication is important so that that participants in a project such as this have a clear sense of the commitment required before joining and that any personal conflicts between members preempted to avoid escalation. In addition, having a clear shared vision of the production and direction through good communication between the director, writers, and actors can also help the production be coherent and successful. An additional factor is equality among participants. In the case of Genki, there were potential barriers to participation due to long distance travel requirements, as well as required financial contributions. These factors should be mitigated as much as possible, by scheduling rehearsal times in such a way that those taking long journeys to participate in rehearsals have their scenes concentrated over a few days to reduce the number of trips required. Ideally, factors such as disparities in income and commuting expenses should also considered when asking for monetary contributions from participants, or alternatively reducing the money offered to scholarships to first cover all operational expenses.

Finally, despite the potential issue mentioned above, Genki has been a long-running and successful grassroots project that has helped foster connections between the local Japanese and foreigner communities through theatre. This project can potentially serve as a guide and inspiration for similar undertakings in other communities across Japan.

\section{References}

Barbee, M. (2016). Drama in the L2 classroom: A defense and practicum. Mask \& Gavel, 5, $5-22$.

Carson, L. (2012). The role of drama in task-based learning: Agency, identity and autonomy. Scenario Journal for Drama and Theatre in Foreign and Second Language Education, 6(2), 46-59.

The Council of Local Authorities for International Relations (CLAIR) (n.d.) The Japan

Exchange Teaching Programme History. Retrieved August 31, 2021 from

http://jetprogramme.org/en/history/

Dodson, S. L. (2002). The educational potential of drama for ESL. Body and language: Intercultural learning through drama, 3, 161-206. 
Dornyei, Z. (1994). Motivation and motivating in the foreign language classroom. The Modern Language Journal, 78(3), 273-284.

GENKI Youth Association (2021a). About GENKI. Retrieved August 27, 2021, from https://tosabenmusical.blogspot.com/p/genki.html

GENKI Youth Association (2021b). Past - English. Retrieved August 27, 2021, from https://tosabenmusical.blogspot.com/p/past.html

Hattori, S. (2019). Japanese dialects. In Diachronic, areal, and typological Linguistics (pp. 368-400). De Gruyter Mouton.

Horghagen, S., \& Josephsson, S. (2010). Theatre as liberation, collaboration and relationship for asylum seekers. Journal of Occupational Science, 17(3), 168-176.

Kochi AJET (n.d.) About [Facebook page]. Retrieved August 31, 2021, from https://www.facebook.com/groups/131450266897640/about

Lóránt, B. (2015). The Lexicon of Kochi Japanese. A comparative analysis between Japanese natives and Japanese non-natives of Kochi.

Okumura, N. (2016). Japanese dialect ideology from Meiji to the present (Doctoral dissertation, Portland State University).

Raquel, M. R. (2015). A sociocultural approach to theatre productions for second language learning. In A. Babayants and H. Fitzimmons Frey (Eds.), Theatre and Learning, (pp. 71-92). Asato Theatre.

Ryan-Scheutz, C., \& Colangelo, L. M. (2004). Full-scale theater production and foreign language learning. Foreign Language Annals, 37(3), 374-385.

Sato, K. (2010). Tosaben Grammar. Tosa Wave, 35, 1. https://www.kochikia.or.jp/info/tosawave/tosawavevol35.pdf

Statistics Japan (2021a). Foreign residents in Japan. Retrieved August 27, 2021, from https://stats-japan.com/t/kiji/11639

Statistics Japan (2021b). Kochi. Retrieved August 27, 2021, from https://statsjapan.com/t/tdfk/kochi

Takahashi, M. (2010). Areas where Tosaben and Hataben are spoken. Tosa Wave, 35, 1. https://www.kochi-kia.or.jp/info/tosawave/tosawavevol35.pdf

Takeuchi, J. D. (2015). Dialect Matters: L2 Speakers' Beliefs and Perceptions About Japanese Dialect. The University of Wisconsin-Madison.

Yashima, T., Zenuk-Nishide, L., \& Shimizu, K. (2004). The influence of attitudes and affect on willingness to communicate and second language communication. Language learning, 54(1), 119-152. 
Yasutake, L. \& Yuen, S. (2010). Useful/interesting Tosaben. Tosa Wave, 35, 3. https://www.kochi-kia.or.jp/info/tosawave/tosawavevol35.pdf

Yoshida, S. (2010). Origins of Tosaben and Hataben. Tosa Wave, 35, 1. https://www.kochikia.or.jp/info/tosawave/tosawavevol35.pdf

Philip Head is a lecturer at Osaka Jogakuin University and a doctoral student at Hiroshima University. His current research interests include the effects of listener language learning background on ratings of L2 English speech comprehensibility and the benefits of shadowing for English speech production and perception. He was a JET Programme ALT in Kochi from 2010 to 2015 and participated in Genki as an

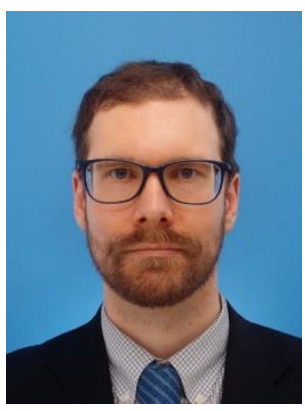
actor, writer, and photographer/videographer.<head@wilmina.ac.jp>

\section{Appendix A}

\section{Survey questions and full responses}

1. How many years were you involved in Genki and in what roles? E.g. 1 year in minor role(s), 1 year props/choreography/writing, 1 year in major role.

2. What was your Japanese ability when you participated in Genki?

3. What was your JLPT level (if known) when you participated in Genki?

4. Did participating in Genki affect your motivation/ability to speak Japanese? If yes, how? If not, why not?

5. Did participating in Genki affect your relationship with the community (co-workers, students, other foreign residents)? If yes, how? If not, why not?

6. What were your reasons for participating in Genki?

7. What was the best thing about participating in Genki? Why?

8. What were some problems with participating in Genki? Why?

9. Any additional comments about your experience with Genki?

Note: The answers to questions 1-3 are discussed in detail in the Participant Profiles section of the paper. 


\section{Did participating in Genki affect your motivation/ability to speak Japanese? If}

$\mathrm{P}$ yes, how? If not, why not?

I wanted a bigger role in order to improve my japanese but my role had one speaking

line over and over, so I was a little disappointed, but I learned from watching other

1 people rehearse.

2 It helped my fluency and pronunciation

It kind of negatively affected my motivation in that the Tosaben dialect and accent was hard to mimic, and it made me wonder if my standard Japanese was up to par. I knew then as I know now that it was irrational thinking but it did make me feel a bit

3 insecure.

Yes. Became interested in words unique to the prefecture's dialects (Hata-ben and

4 Tosa-ben), increases motivation to study for JLPT

Yes. I learned a good deal of vocabulary from memorizing lines. Performing also

5 helped me learn to speak with more expression.

6 Yes - fostered interest in Tosa-ben

My Japanese ability improved thanks to my third year on Genki. Pronunciation and

7 fluency drastically improved. Probably no change to grammar.

Yes, it made me much more interested in the local dialect, and I had plenty of incentive to speak Japanese to communicate with the many non-English speakers

8 involved with putting on the shows.

It definitely helped bolster my confidence in learning Japanese, after the first year as a cast member I walked away with feeling that if I could manage Tosa-ben I can manage

9 regular Japanese just fine.

I only had English lines so it didn't help my Japanese speaking ability. However, listening to the other actors helped my Japanese listening skills. Participating in Genki Musical did motivate me to learn more Japanese and appreciate collaboration between

10 foreigners and Japanese people.

I was already in a town where I had to speak JP all day, so I actually spoke more

English in GENKI than in my workdays. I imagine if I worked in the city it would be

11 reversed.

Not necessarily as I was already quite proficient, but it allowed me to learn more about

12 the Tosa accent.

13 Honestly, probably not. It just wasn't really needed behind the curtain. 
Yes, definitely. It exposed me to the local dialect and gave me a chance to see other

14 foreigners working hard to perform in Japanese as well.

Yes. It had a positive effect on both motivation and ability. Meeting people in a bilingual environment helped ease nervousness about communicating and speaking Tosaben on stage boosted my confidence levels. Meeting local Japanese people gave me reason to practise spoken Japanese more often and the rehearsals and emphasis on

15 intonation and accent helped reinforce natural speech patterns.

It helped me learn and understand more about the local dialect than I would have on my own. I spoke and studied the same amount before and after the musical though.

16 (Which was a fair amount).

It did not boost my motivation in any large and direct way, but it got me excited about

17 Tosa-ben and likely boosted my confidence.

Yes! It was so much fun to participate and made learning the language less intimidating. It was especially helpful to have dialect experts and locals coach us on our accents. To be able to perform with confidence helped me apply what I learned to

18 my interactions outside of the musical.

When I took the speaking roles, I got native feedback on my lines which helped improve my ability to speak Japanese and I practiced a lot. It helped maintain my

19 motivation to speak Japanese and didn't hurt it.

20 Yes, but not speak japanese. I like history.

It was a lot of fun to play with Tosaben and sing in Japanese. After becoming more fluent in Japanese, it was more fun for me to participate in the musical because I was more able to ad lib or improvise if I or someone else forgot a line. I learned a few new

21 words and ideas, but I think the main ability improvement for me was pronunciation. I would say not so much in the first two. I more participated for social reasons. I was more motivated in the third year because I had a larger role and wanted to make sure I performed well. Spending so much time learning my lines and practicing with cast

22 certainly correlated to more confidence speaking Japanese outside of the musical.

23 yes

Yes, a little, in that it taught me some vocab I didn't know (like "taiyou" for "sun"!) Including words in Tosaben (of course) and it actually helped when conversing particularly with older people in my town, especially using the different verb

24 conjugations, because of how strong their Tosaben could be. 
Yes, it was motivating to have small group tuitions with a native speaker. It was also

25 nice to be complimented on my learnings from it.

It gave me an outlet to learn more Japanese and learn words that I wouldn't have

26 learned in any other situation.

Probably not. I already had a high level of Japanese ability and spoke Japanese with

27 my coworkers and neighbors daily.

Yes. It made me want to study intonation more and drastically helped my speaking

28 ability.

Yes, it did but rather than motivate me to speak Japanese, it made me want to learn

Tosaben. I think the reason for this is that when I was practicing my lines or a scene from the musical, everything was in Tosaben. As a result of being exposed to Tosaben

I slowly learned words, grammar and the specifics of Tosaben pronunciation and it

29 made me want to learn more.

Since I had not studied Japanese before coming to Japan, Genki was one of the first exposures to a type of formalized Japanese language study I had, and I was able study Japanese in a way that emphasized speaking (most important skill for my immediate needs in Kochi). When acting, you need to know the tone of what you are saying, how your lines interacts with other actors' lines, and general pacing of a scene, which forces you to translate and internalize the Japanese vocab/grammar (Tosa-ben) you are interacting with.

For my second and third years I became more comfortable with speaking Japanese and focused on reading comprehension for the script- by translating the script I was able to increase the amount of kanji I knew, and I incorporated the genki script into my overall study plan for the summer N4 JLPT (maybe not a great idea since Tosa-ben is

30 very different from standard Japanese!)

I would say it improved my speaking ability, but I already had a high motivation

31 beforehand, so that remained unchanged

32 Yes - it motivated me to learn another dialect of Japanese (Tosa-ben)

Yes it definitely did. I was starting to learn Japanese but Genki encouraged me to explore Tosa Ben the dialect in the Kochi area. My lines in the show needed to be delivered in a very strong Tosa Ben accent so I was keen to do it right and get across

33 the right humour. I concentrated on learning this dialect. 
Hmmmmm for me not so much as it was in a heavy Tosa ben accent which I didn't see the use for it outside of kochi. Although it was fun at the time whilst in kochi, I was

34 conscious of sounding like a 'country men' everywhere else in Japan ie Tokyo Yes and no. I was so busy most of the time that I didn't have a chance to focus on

35 learning Japanese beyond what was required for my role.

\footnotetext{
Did participating in Genki affect your relationship with the community (co-

$\mathrm{P}$ workers, students, other foreign residents)? If yes, how? If not, why not?

Yes, it improved my relationship with the community somewhat. I enjoyed working with some of the other JETs and my relationships with many cast/crew improved, but my opinion of some participants/staff improved. I was happy to receive support from

1 friends/coworkers who came to see the shows. It improved my relationship with my fellow ALTs as well as gave me more Japanese
2 people to communicate with

It strengthened some relationships while at the same time souring others, especially

3 the bossy, easily-irritable members. I don't work well with such people.

4 Yes- friendships among ALTs and other foreign residents

Genki had a huge impact on my relationships within the community. I made my best friends through Genki and got to know many, many more people than if I hadn't participated. I'm fairly shy and having a shared project over a period of time allowed me to get to know people, and gave me the time to come out of my shell. It also improved my relationship with one of my JTEs. She was initially skeptical of me when I replaced her favorite ALT, but after seeing me sing and dance she was much 5 friendlier.

No - my office didn't really care about the musical, unfortunately, as they had different

6 priorities at the time
Yes, a little. I already had a good relationship with co-workers by my third year. They were impressed by my performance in the musical. It was a conversation piece when speaking to local residents who I would make conversation with (discussions about
7 occupation, hobbies, love of Japanese etc.)
Yes. I felt much more linked to the people of Kochi because we were performing for them in their (terribly-accented) language and travelling to all corners of the prefecture
8 to do so. I also got to know everyone who helped the musicals much better than if I 
had not been involved, and this included many JETs, locals and other foreign residents.

I was able to make a lot of new friends during my time as a cast member, meeting

9 people i wouldn't get to usually due to the distance they lived from the city.

It brought me closer to my fellow JETs because of all the time we spent together practicing. As I didn't have any Japanese lines, I didn't work directly with a native Japanese speaker to rehearse my lines. So, I didn't personally grow closer to any Japanese natives. However, touring Kochi with our production and seeing the reaction of Japanese people to the performance did make me feel closer to the Japanese 10 community.

11 Yes! I made a lot of friends and was able to integrate into the community better. Yes, it allowed me to bond with other JET participants and Japanese people who lived

12 in Kochi city who helped out.

Yes, received a lot of interest, mostly from coworkers. Definitely helped me get to

13 know other JETs.

I didn't feel any long-term effects, but by performing at many different areas in Shikoku I got to interact with a wide variety of Japanese people across the prefecture and make them laugh That definitely made me feel more welcome in the community. Relationships-wise I got closer mainly with my fellow cast members, not

14 the larger community.

Yes, in a mostly positive way. I gained more friends - both Japanese and other foreign residents. I gained knowledge of local culture (through the mixing of local and western storytelling aspects in the musical). I was able to use some of the language I picked up during rehearsals in my daily life, helping me make connections with the aunties in my local area. I had a positive conversation point at work, with neighbours and friends and they appreciated my attempts to understand and use Tosaben. There was one unfortunate event with one local resident who had joined Genki, who had been awkward but kind, but they essentially ended up stalking some other Genki participants, which caused quite a bit of tension in the international community at the 15 time.

Yes, I got to know more people in Kochi and it was nice to see interactions with the audience and the plays. It didn't affect my interaction in the long term since my

16 village where I worked was fairly removed from Kochi. 
It greatly improved my relationship with other JETs on the musical and it improved

17 my relationship with many different community members that I invited.

Absolutely. Friendships were made both within the expat community as well as with other Kochi citizens. I found my coworkers appreciated my effort as I believed it showed my investment in the community. Nothing bonds people together like activity and I made some lifelong friends in that musical group! Many of whom I still speak

18 with regularly.

Yes! Genki had a great sense of community where we came together with other foreign residents with the same purpose of working together to make the musical happen and helping each other out which was all voluntary on our part. My coworkers and students were not involved but I did make friends with Japanese native volunteers

19 too. I got to know everyone really well, especially with the camp we did every year.

20 Yes, I like if I have many friends around the world

Most definitely, I met many people in the foreign community thanks to the musical. Some of them I am still friends with to this day, years after performing. I think the play attracted people with similar interests (such as community involvement and artistic performance), which helped me to be comfortable and become friends with 21 them.

Definitely with my co-workers! Telling them about the musical and seeing how hard I was working to learn my lines was a neat conversation starter. They were eager to learn more about the musical and teach me some Tosaben. My students got a kick of photos of me in costume and videos of me performing. They appreciated the effort of

22 me taking part in Japanese culture.

23 yes

Yes, it helped me simply by getting me out the door. I lived in the countryside and I'm an introvert, so participating in Genki was a way to force myself to try to connect with other JETS/ Foreignors living in my prefecture. It was the best choice I made on that front, I enjoyed hanging out with the other participants. My relationships were good already with my community and students and the like, and that remained largely

24 unchanged.

Yes, my colleagues were impressed that I took part in it. They supported me by

25 coming out to see the musical.

26 It allowed me to make friends and have a social outlet. 
It gave me more exposure to the prefecture and allowed me to visit places I otherwise wouldn't have. Through this I got to know the other JETs in Genki quite well and

27 interacted with many of the locals when we performed in their towns.

I think so. I think my BoE enjoyed seeing me participate. It was a good conversation

28 starter too, and my students enjoyed seeing me put myself out there.

Yes, it did. I think the fact that it was not only a musical but also a fundraiser to financially help students in Kochi study abroad made it an event that people all over Kochi were interested in seeing. Furthermore, the novelty of it being a musical in the Kochi dialect managed and performed by foreign residents in Kochi made it a spectacle that was sure to attract people's attention. I think everyone that saw the performances were always amazed. Maybe they also felt thankful that foreigners were making the effort to share their love for both the culture and the language of Kochi through this musical. As for foreign residents, the people who participate in the musical all grew stronger out of both necessity and also as the result of being part of the musical. I feel that the performances would suffer if the relationship of everyone involved in the musical wasn't a strong one. Foreigners who see it, might also become interested in joining the following year. Overall, I think that Genki has a positive

29 effect on the community and everyone involved in putting on the musical.

Yes, my co-workers and students were highly supportive of me participating in Genki, and would actually help me with my lines during down-time at school. With the local Japanese community, I made friends with people who I would not have otherwise met, such as local translators, event space organizers, media personnel, etc. With the AJET/foreign community, it definitely deepened my bonds with other ALTs and CIRs (from JET or other programs), Kochi University students, and long-term expats in Kochi. Since I lived in Kochi City and had a large apartment, I would host 3-4 Genki cast/crew each weekend, which definitely helped with making new friends and getting

30 involved with community events.

It definitely improved my relationships with fellow ALTs, but outside of that, I don't

31 think it really had an effect on those with my community

Yes, I developed deeper relationships with the volunteers and foreign resident

32 cast/crew. It was a talking point when interacting with my students and coworkers.

Yes I met a lot of Foreign residents and other teachers who were involved in the

33 musical. I also met a lot of Japanese people through the musical also. My Japanese 
improved because I needed to use Japanese to communicate with the non English speakers and this motivated me to try and speak Japanese whenever I got the chance.

Yep. Some of my students and teachers from the school were there. I became a sort of 'mini celeb' when went back to school. Although the game didn't last long

34 before it went back to normal lol

Yes. It allowed my Japanese friends in the community to connect with the foreign community in a more personal way through shared appreciation and respect for

35 differing cultures.

\section{$\mathrm{P} \quad$ What were your reasons for participating in Genki?}

I was interested in doing something with which I had no experience (theater), I was interested in community outreach/charity, I was interested in having something to do during the lonely, dull winter months, other ALTs had recommended joining the

1 performance, etc.

Finding a peer group during my first year and then to continue with the community

2 aspect in the years afterwards

3 Social connection

4 Other JETs in my area were participating and I didn't want to be left out

I love musicals in general, and I love to sing and dance. I never thought of myself as much of an actor, but the organizers made it very clear that everyone was welcome and there were no prerequisites. I was excited to get on stage and perform. I had never

5 been in a musical, but I had done some dance performances.

6 Love of theatre and singing First year was to do something with my peers. It looked like fun.

The third year was for many reasons: I love creating costumes and props and could help. I love dancing and wanted to help with making dances. I wanted to improve my Japanese. I wanted to be a part of the process from start to finish, this included story development, poster deployment, selling tickets, touring and performing. It was an

7 experience I wanted to take part in fully, perhaps as it was my last year in Japan. One of the first things that veteran JETs had told me when I arrived in Kochi was how much fun Genki was. (They were right.) I'd been involved in performances at school and university, so I wasn't put off by being on stage, going to rehearsals, etc. I also

8 wanted to use the opportunity to get to know the community better. 
To commit to a "say yes" mentality during my time in Japan, someone asked if I

9 wanted to do it and I said yes.

It looked like a fun and unique experience. Plus it's kind of a right of passage for

10 Kochi JETs.

11 I wanted to do something social.

12 To connect with other JET participants and other Japanese people outside my town.

I mostly just wanted to engage with other JETs, but I also worked on plays for many years before JET, so I felt like I had experience to contribute. Also a good opportunity

13 to visit other parts of the prefecture.

To get to know other JETs, for fun, to practice my Japanese, to interact with the

14 community outside of the classroom, to volunteer

15 Learn more about the local dialect, meet new people and I wanted to dance.

I always liked theater and then I got frustrated with how poorly led some of the productions were, so I wanted to create a play that had a more meaningful impact on the community. That frustration led me into writing and directing the musical my

16 second year I was involved.

17 Fun, volunteering / charity, community-building, culture-building

18 I love theatre, improving my language acquisition and challenging myself.

Community involvement, practicing Japanese (especially the local dialect), a way to make friends with similar interests and for the fun activities that came along with

19 volunteering

20 Love it

21 I love acting, and I had heard it was an excellent event in the Kochi community.

The first couple of years, the reason was mainly social. I wanted an opportunity to meet more folks in the prefecture and have a fun activity during the winter. I also was involved in theater in high school and college, so it seemed like a natural fit. My third year, I was definitely interested in a larger role as I had been more focused on studying Japanese. I looked at it as a challenge and felt good about the result after a lot of hard

22 work.

23 community

Primarily, to get out and try to socialize and connect with the other foreigners in my prefecture. Which worked! And also because I missed acting. I've never been good at

24 it, but I love being part of the theater nonetheless. 
25 Have fun with fellow JETs while learning the local dialect.

26 I like musical theatre and wanted to do it.

I did theater as a child up through high school and wanted to get back into it. I also wanted to connect with the other JETs more (I was placed in a very rural and isolated

27 location).

28 Volunteer work, improving Japanese ability, making friends

There were a few reasons why I joined Genki. The first one is that I needed something to do during the winter. It was getting cold and I was starting to get a little bit depressed. The second reason is that I had gotten a taste of performing when I participated in a 24 hour theater project in university and was looking for another opportunity to perform. I did not think it would be in Kochi nor under the form of a musical in the Kochi dialect, but when I heard about this musical, I knew I had to participate. The third reason is that I was fascinated by Tosaben. Every day, I heard it all around me, but for the most part I never understood what was being said. By participating in this musical, I would be able to learn more Tosaben. The fourth reason is that I like challenging myself. I had never participated in a musical so given the opportunity to do so, I thought this would be a good challenge. The fifth reason is that I had seen many musicals performed by my theater friends in university so given the 29 opportunity to do it myself, I jumped at the chance.

My predecessor was involved with Genki so my school really encouraged me to join, since they knew that I was interested in learning more Tosa-ben. I didn't have experience in theatre or musicals before coming to Japan, but I always enjoyed watching them and thought it would be fun to have an artistic outlet in addition to the

30 Kochi sports groups I was in.

31 I wanted to get better at Japanese, as well as step outside of my comfort zone I wanted to be involved in the local community; I had an interest in the performing arts; I wanted the experiences of helping drive a large project as a director; and I

32 wanted to use and deepen my understanding of Japanese.

I joined Genki to meet other teachers and expand my network. I wanted to meet some new people and I also wanted to have a laugh. I also joined for the opportunity to 33 practice Japanese in a fun way.

Get to know the other JETs better. Also, it was a way for me to explore and learn more

34 about kochi Ken as a whole and not just the city. 
35 I was drawn to the positive influence that Genki could have on the local community.

\begin{tabular}{ll}
\hline $\mathrm{P}$ & What was the best thing about participating in Genki? Why? \\
\hline & Working with other cast members, particularly when it came to the songs and dancing, \\
& was a lot of fun. The cooperation and instruction were particularly great the year I \\
1 & joined (2015). \\
\hline 2 & The sense of community, purpose and friendships formed \\
\hline 3 & Social connection \\
\hline 4 & Community among participants \\
\hline
\end{tabular}

The best part about participating in Genki was spending time with really awesome people, and having the shared experience of bringing the show to life. Touring the

5 prefecture was such a blast, I looked forward to it every year.

I loved how free we were to define our own roles (e.g. Composing songs, directing,

6 producing set/props)

I'm really proud of the way I went from being unable to read a complete line of

Japanese/Tosaben to being able to read my lines (with Kanji) perfectly and recite my lines almost perfectly (I had a few lines removed for memory). The worried faces around the table when I struggled to read my lines that first day motivated me to show

7 them how much I could improve (in a good way. I knew it would take commitment).

Helping people with talent to show off their talent by doing cool things. We had amazing singers, songwriters, dancers, choreographers, artists, costume designers, comedians, writers. I'm not good at any of those things, but I am good at organising and encouraging people, so I was able to help bring all of those people together to

8 make something we could all be proud of.

Definitely the camaraderie, you're able to see a bunch of people with a common goal banding together (sometimes literally) from rehearsal to performances. There's a

9 special type of bond formed there that I don't think any of us will forget about.

The performances were great but my favorite part was rehearsing together and in the process, growing closer to everyone involved. This was my favorite part because of all

10 the memories I made.

The social aspect; I lived in a small town with only obaasans and ojiisans, so it was

11 nice to be able to communicate with people my own age.

12 Building community with other people. 
13 Community building inside the JET community, community outreach to Kochi

The original script, the creativity of the crew, the joy of performing live to an audience, the retreat we do with the full cast, working on something creative with a

14 team of people (I forgot how much I've missed that)

The people. Some of those friendships made or reinforced during Genki have lasted

15 for years.

The best thing was bringing together the ALT and CIR JET members to learn and practice speaking and preforming in Japanese and working with local volunteers to create an international production. It was great to see people with all different levels of language and theater experience put time in to create something for the local

16 community to watch and enjoy.

Working together to create something and building a connection between JETs and the

17 people of Kochi.

The confidence I gained and the friendships I made. I lived in the countryside so social events were not as accessible. Participating with everyone helped me feel connected to

18 the JET community and allowed me to see a lot of Kochi!

The sense of community with the volunteers and even for those we performed for. A lot of fun came out of participating in all aspects of the musical. It left the biggest

19 impression on me and fills me with a lot of good memories and experiences in Japan.

20 Acting. Sometimes we need other activity other than usually we do.

Probably making cool memories with cool people. It's still a touchstone for times I hang out with my old Genki friends. Also, directing and acting in the plays were a lot

21 of fun!

I loved the camaraderie shared with the cast and crew while traveling around the prefecture. I didn't have a car while in Kochi, so getting to take those road trips were a fantastic way to explore Kochi-ken, meet local people, and foster deeper friendships

22 with other ALTs.

23 community

Making friends with other JETs and hanging out. I really struggled getting out and socializing, especially from being out in the countryside, so being part of Genki got

24 me in contact with amazing and fun people and I'm super grateful for that.

Having fun with local JETs while receiving compliments from my colleagues for my

25 effort in learning the local dialect. 
26 Being able to sing and perform every week.

Selfishly, I just loved being on stage, and having the right mix of abilities (I could sing and speak Japanese) gave me the opportunity to be in major roles each year. I also loved making friends with the other JETs (I met my wife, also a JET, while doing Genki), and I thought the mission of Genki was great: grassroots internationalization

27 and raising funds for scholarships to send Japanese students abroad.

28 Making memories and helping the community through grassroots internationalization. There were so many things that I enjoyed about participating in Genki. If I had to choose just one, I would say it was the performances. Throughout the performances we could see how all of our hard work during the rehearsals paid off and we could also see the smiles we were putting on everyone in the audience's faces as the language and the culture of Kochi came to life through the musical. There was also this so-called Genki magic where, by the time we got to the performances, everything would always come together almost by magic nevermind technical difficulties and lines and songs that hadn't been completely memorized. It just seemed that at the time of performances, everyone wanted to put on a good show and wouldn't let anything ruin 29 that.

The community aspect of it, and the way that the Japanese community embraced it. Three of my best friends from Kochi came from our mutual involvement with Genki. It was difficult sometimes, especially as director, to ensure that everyone was working hard and having fun, but the set-up that was present during my three years of participation fostered a nice atmosphere overall (lots of team-building opportunities, outside practice events, and making sure everyone felt like they were contributing to the event in a unique way). Also, we got to travel the entire prefecture, which was nice, especially when visiting some smaller towns. My favorite performance was in

30 Akaoka-cho, where we got to perform on a traditional kabuki theatre stage.

It left me with some great memories, and seeing the surprise on someone's face when

31 I'd throw out some Tosaben here and there was pretty amusing.

Sharing the enjoyment of the process with the volunteers, cast and crew, especially the

32 live shows, and seeing everyone's hard work come together.

The best thing was definitely the people I met through it and the fun rehearsing. I also

33 loved learning Japanese and particularly Tosa Ben in a fun way. 
After having done, felt the accomplishment to be part of something well put together,

34 given the limited resources that we had. The experience afterwards was the best bit.

Being able to form stronger relationships with other participants through a shared

35 vision and goal.

$\mathrm{P}$ What were some problems with participating in Genki? Why?

I had to sit around long hours during rehearsal a lot bc I had a small role. Rehearsal schedules weren't particularly efficient. Also, outside of the flyer and a radio appearance, there was little effort put into promotion therefore we didn't get the exposure necessary to raise awareness or receive additional donations. Cast and crew had to contribute a lot of money in order for the show to even happy and in the end, we could've just pooled that money into the donation pot and ended up with more money than we actually raised from performances. Finally, the leadership was a bit impatient at times and didn't really treat us with respect during the tour. Still, it was an

1 overall positive experience.

Inevitably there is drama. It's an intense four months, and it is hard for people to commit to the entire time, skills aren't always a match, interpersonal conflicts happen. Depending the level of commitment, you can get some people pulling some hellish sabotage on the others. It's the flip side of any group effort and after 3 years it burned

2 me out, even if I really appreciated my first 2 years.

The hectic schedules and some group activities that seemed interminable. I can't remember specific ones but I do remember they just seemed to stretch out

3 unnecessarily long.

4 It was quite far to travel every weekend from the Hata-gun area.

I can't think of many problems. Rehearsing in a very cold gymnasium was uncomfortable at times. Some cast members were more motivated to learn their parts

5 than others, but it generally worked out in the end.

Kochi is quite a big prefecture and the fact that everything was run out of Kochi city meant that the time investment for some people was inevitably a lot bigger in order to

6 account for hours of travel every weekend. This could be quite exhausting! It is an intense and time consuming event. It was the reason I didn't participate in my 7 2nd year. 
It sucked up almost all of my non-work time for about 5 months of each year. I didn't regret this, but maybe I could have been a better ALT if I had used some of that time

8 to work on my teaching skills.

Explaining to my Japanese co-teachers and Japanese colleagues what this was about,

9 why they should see it. For some reason it just never clicked with them.

Aside from technical issues at certain venues, I think we could have brought more audience out to the smaller showings. We put a lot of effort into the production and it would've been nice if more people knew about it. However, I realize that this isn't an

10 easy problem to solve.

I took part in the year of Shintakarajima. There was some breakdown between

11 organizers and participants.

Not sure if this is a problem per say, but other than donations, I never really knew/saw/understood the impact of what we did or what viewers/audience thought of 12 it.

13 Time consuming, occasional creative differences and minor dramas Sometimes lack of coordination/planning, large time commitment, It really depends on the people in charge for the year. If you have leadership that really care, it can be an amazing experience, but for that to happen, people have to be passionate about it how much of that energy makes it into the musical tends to vary from year to year (2) You have to craft the best show you can with the available talent and "genki"ness of 14 the participants.

Tiredness, especially on the last two weekends of back to back performances. You give Genki all your weekends for months, so you have to put any other events on the

15 back burner for a bit.

The problems come from the writing of the musicals and the time restraints on production. Creating a play that makes sense culturally in Japan to Japanese audiences was not always a concern and since each act is traditionally written by a different person, the play can seem very disjointed and completely nonsensical with no running plot. This means that the audience doesn't get interested and the community engagement piece is lacking. It also means that funds for the play then suffer. It also is a task that Kochi CIRs are forced into without a lot of guidance which can be tricky. I

16 don't think crating a play works as a coop, I think you need a dedicated writer or 
director creating a plot and story that makes sense. It's not always possible with the members of JET who are there.

Time commitment, difficulties in coordinating large numbers of people, creating a high-quality creative work with many different creators and many different target

17 audiences

I remember it did require a lot of time, and the second year I was unable to commit to

18 the schedule as an actor but I was able to do the lighting.

Some people were focused on perfection and only looked at what was lacking (without constructive criticism) rather than what was accomplished, which could dampen excitement to be involved and motivation to continue. We had some financial problems too (i.e. a very limited budget) in which we would have to pitch in personally to help pay for logistics. There was no technical training for equipment we would borrow at venues, and some equipment was old and not safe to use (for example, some of the lighting switches would be sparking) which greatened the risk to

19 some people's safety.

20 Communication. Want to talk to other members, but not too much English vocabulary The time schedule is brutal. Every weekend for months is a big commitment, and is not feasible for me after finding non-ALT work. Also, sometimes interpersonal

21 conflict was irritating and stressful.

I honestly don't remember many! Sometimes rehearsal would start late because people would be out drinking the night before haha. I can't recall anything major going wrong with venues or performances. It could be a big time commitment but definitely worth 22 it.

\section{3 none}

The only problem I had was that it was definitely a bit of a commute for me. I did not like the hour to hour and a half commute there and then same back, and then paying for parking because typically to stay with a friend in the city I gotta park somewhere.

24 But, that's it. I can't think of any other problems I had.

Some other participants weren't as committed to the musical and it made rehearsal 25 difficult.

Our performances were all cancelled due to coronavirus. It took up a lot of my time 26 and was a very big commitment.

27 There were always some personality conflicts, but mostly we all got along. 
If people didn't put in the time required it hurt the production. It's a lot to ask of people to give up their weekends for three months, but the more successful productions had casts that knew what they signed up for. The worst year was a year when the director only showed up half the time due to work and life commitments. That's what inspired me to direct the following year. I think the success can also be really dependent on the talent pool of volunteers for that year, and getting people to

28 volunteer some years was easier than others.

I don't think there were any major problems, but there were a few minor issues. I think the most important one was commitment to the musical. Because participation was voluntary and there wasn't really a competition to find performers, everyone was allowed to participate. Because rehearsals were on the weekends and there wasn't really any punishment for being late or missing a rehearsal, it was hard to make sure everyone attended rehearsals. While it wouldn't punish the individual who was late or who didn't attend, it did affect all the other performers since they relied on the person to be there in order to get used to saying their lines in conjunction with the other performers. This also meant that sometimes a character or a song had to be removed completely because the person who was late or never attended rehearsal had to be removed from the musical half way through the production. As a result, the musical's story had to be changed in order to compensate for a character or a song being removed. Another issue was the director's ambitious vision. I feel that sometimes the director's would have a vision for the story of the musical that did not take into consideration the fact that everyone who was participating were not only volunteers but also had different levels of acting, singing and dancing experience. As a result, some people would feel overwhelmed during rehearsals due to the stress to get the dance moves or their lines right. As I mentioned previously, some way or another, it always came together, but there were definitely some rehearsals where people felt miserable and even broke down crying. Another $t$ issue was advertising the actual event. While I really enjoyed performing, I always felt bad about the turnouts. It always seemed that we would advertise the musical at the last minute and even sometimes just before a performance. I feel that if we had made a more sustained effort earlier on to advertise the musical and not only through the use of posters, we would have been able to attract more people and it would also have been an even 29 people would not only be aware of but look forward to each year. It always seemed to 
come as a surprise to the attendees that we were once again doing the musical. I also don't feel like enough effort was made to emphasize the fact that the musical was not only a musical but also a way to raise money to help students in Kochi study abroad. The last issue was sustainability. It never became an issue, but I could see it being the case that there were not enough people to put on the musical. Sure it was easy enough to find performers, but it was always a challenge to find people to make props, manage lights and music.

As an actor, finding motivation to go to practice (especially during cherry blossom season), and as director, motivating everyone to come to practice.

On a general note, ensuring that musicals were funny and entertaining, but also appropriate and inclusive of cast, crew, and audience members. When I was director, there was a cast member who came up with a costume idea which involved drag as a comedic element. While that is common in Japan, I knew there were gender nonconforming/non-binary members of the foreign community in Kochi who would feel excluded or made fun of by that choice. A similar concern is how Kochi people are portrayed, specifically with drinking. I think Kochi people do embrace alcohol culture as a whole, but making sure that when it is brought up in Genki that is does not come across as mean-spirited is very important.

When developing the 2016-2018 scripts, we also had different people write different acts (3-5 writers for each script), so the tone, messages, and song choices were sometimes at odds, which required a lot of tine-tuning. Also, finding members of the Japanese community to translate the script from English --> Japanese --> Tosa-ben. We were often rewriting the script during practices with the help of native Tosa-ben 30 speakers who found errors from the original translations.

I didn't have any problems personally, but I know it was difficult for some of those who lived further away from the city (Tosashimizu, for example) to make it to 31 practices every weekend.

32 Can't think of any.

33 No problems.

Rehearsing and trying to memorise the lines $(\hat{0}$. My Japanese wasn't strong at the

34 time and it was in a new dialect not taught in books. Only way was just to 'memorise' 
There is a lack of support from the local Kochi government. Without an official guiding body, it is incredibly difficult for the people in charge to create a successful

35 musical with the limited time and resources available.

\section{P Any additional comments about your experience with Genki?}

I am happy I did it but the experience was a little oversold in my opinion. People said it's the best thing you'll do on JET, and while I'm glad I joined, it probably doesn't

1 even rank in the top 10-15 things I've done/achieved/experienced whilst in Japan.

I think its a net gain for any ALT, but there will always be people who sabotage the efforts of others and that was too much in the end and I couldn't do it the last two years

2 I was a JET.

3 It was a lot of fun, and I highly recommend it to future JETs.

4 [No response]

Genki is one of the things I miss most about living in Kochi. There is really nothing else like it. It's such a great way to celebrate Tosaben and it helps us foreigners to engage with the language, culture, and history of the area. I think it's also important as a way of connecting with local people who may have little to no interaction with nonJapanese folks in their day to day lives. If we're willing to get on stage and look a little

5 foolish, we become more approachable.

It seems that the musical is currently an online only experience due to a combination of the pandemic and lack of interest. This seems like such a shame to me as it was

6 such a good way to feel closer to the local community!

I loved it. Not only do the funds raised from ticket sales help with scholarships, it's something the residents of Kochi can be proud of. It's also really good conversation

7 topic!

We often treated it as a bit of an afterthought, but Genki is actually a fundraiser. As director I not only helped count the money and figure out the bottom line, but I was part of the committee who reviewed the scholarship applications and decided on grants. As I recall in my final year we had made an unusually large profit, so we were able to help 3 Kochi students study abroad that year. Having left Japan later that year I never had an opportunity to find out what happened to those students, but I really hope that they've gone onto brilliant careers and that they got as much out of their time 8 abroad as I did from living in Kochi. 
9 I hope it's able to continue for future teachers to also be able to participate in.

10 Genki Musical is great and I hope it continues for years to come.

11 I would absolutely do it again.

12 N/A

I love GENKI as an act of community engagement. It shows the community we are interested in our adopted culture while simultaneously giving us an outlet to express

13 ourselves. Puts the "E" in JET, as I always like to say.

14 It was a fun ride! I am very happy I did it during my time on JET.

I loved it both years I was a part of it and the years I got to watch it too. Living in

Kochi City meant that lots of people from the rest of the prefecture would ask to crash

15 at your place for the weekends during rehearsal season.

I had a great time and I wish I had gone for it and directed another play my final year.

It was a great experience leading people and very creative for me. I also really enjoyed

thinking about what children and people in Kochi would enjoy watching and then

having them come and react so positively to everything we worked on and enjoy all

16 the jokes and references we made:

17 I'm so grateful I was able to participate in Genki. <3

I will always treasure the time I participated in Genki. It has been almost 10 years and

18 I can still remember most of the lines and songs!

19 I'm thankful I got to participate and would love to do it again!

20 I hope that event continuous every year.

For me, it was a defining part of my JET experience, so much so that I continued after leaving JET. It also helped introduce me to members of the foreign community at a

21 time when I was in my "down" part of culture shock.

It was one of the most meaningful experiences I had while living Japan. Knowing the proceeds went to a good cause made it even better. Participating in the musicals made

22 me feel more connected to Kochi, its history, and its people.

23 gratifying to perform/ accomplish as a group. language ability improved

Enjoyed the heck out of it! It really was a shame, the show for 2020 was honestly going to be amazing and the director had written SUCH a great play. Not having had the chance to film it in its entirety and having had it canceled the week before performances because of the pandemic? Disappointment will linger for a while, but

242021 's online play is hopefully going to at least somewhat make up for it! 
25 Overall, highly recommend people give it a try!

26 It was really good and I'm waiting for an opportunity to participate again.

27 I love that Genki is still going strong after 20+ years!

I feel like it's dying, and that it's harder and harder to get the younger generation to donate their time, but I hope it can survive for many years to come because I honestly feel like it's a great way for the international community to give back and build 28 bridges with Kochi.

29 [No response]

It was definitely a defining event throughout my three years in Kochi, and I am proud

30 to have been a part of it!

31 All-in-all a great experience, and I'd highly recommend it to anyone!

I have spoke with many foreign and former-foreign nationals about their experiences in their local communities throughout Japan, and virtually none of them had an institution like the Genki Tosa-ben musical to participate in. I believe it is very unique

32 and I feel fortunate to have had the opportunity to participate in it.

33 [No response]

When I came back to London, I met a guy from Kochi news paper who found me whilst he was visiting London. And he asked if he could write an article about my

34 experience. I'll share the link

Overall, it was a positive experience but I don't believe Genki really contributes to the community in a way that is beneficial for all the time and effort that's required. If the local Japanese government and community were more involved, beyond just attending

35 the performances, I think it would have a more lasting impact. 